\title{
A New Pitch Angle Control Method of Wind Turbine Generators Based on Feedforward Wind Speed Information
}

\author{
Mouayad Sahib ${ }^{1, *}$ and Thaker Nayl ${ }^{1}$ \\ ${ }^{1}$ University of Information Technology and Communications, College of Engineering, Baghdad, Iraq
}

\begin{abstract}
In this work, a new strategy to control the pitch angle of wind turbine generator is proposed. The strategy is based on designing an intelligent control system capable of maintaining a stable minimum fluctuating power generation. This can be achieved by providing the wind speed information to the controller in advance and hence allowing the controller to take the optimum action in controlling the blade pitch angle. A model based optimizer uses Model Predictive Control (MPC) technique to predict the wind turbine generator future behaviour and select the optimal control actions assisted by the wind speed information while satisfying the power generation constraints. The simulation results show that a significant improvement can be made using the proposed control method.
\end{abstract}

\section{Introduction}

Nowadays, the world is testifying an increasing demand of using renewable energy sources. Among these various energy sources is wind. Wind turbine generator (WTG) is a system that converts the wind's kinetic energy into electrical energy. WTG become the most prevalent power generation resource for its clean and low maintenance factors [1]. One of the operational challenges for WTG is the oscillations in the output power caused by the varying speed of wind. As a result, this variability leads to a difficult conversion of constant energy and thus a control system is needed. One solution to control fluctuating power generation is through blade pitch angle control [2].

With respect to wind speed, WTG has three regions of operation; stop region, partial-load region, and fullload region [3]. Figure 1, shows the generated output power and the variation rang of the blade pitch angle beta as a function of the wind speed. When the wind is below the cut-in speed value the WTG rotational speed is zero and it does not generate any power. If the wind is above the cut-in and below the rated speed values the control system is utilized to capture maximum power from the wind. This control method is termed as maximum power point tracking (MPPT) [4]. When the wind speed exceeds the rated value the pitch angle control is activated to maintain the generated output power constant at its rated value [5].

In pitch angle control the angle of the WTG blades are changed as a control variable for power regulation above the rated wind speed. The proportional-integral (PI) is the conventional controller type for pitch angle control [6]. Despite its simplicity, PI controller may not achieve the intended optimum performance due to the nonlinear dynamics of the WTG [7]. To compensate for the unknown time-varying nonlinearities and disturbances various control structures has been used such as nonlinear PI (N-PI) [8], fractional PI [9], cascade control structure [10] and Fault-tolerant control (FTU) to Compensate for the pitch actuator fault [11]. Other strategies to enhance the pitch control include; fuzzy logic control (FLC) [12][13][14], observer-based bladepitch controller [15] and finite-frequency identification PI controller [16].

Knowledge of future wind conditions assisting model predictive control (MPC) has also been proposed in literature [17]. MPC enables optimal solution while considering system constraints. In addition, it can predict behaviour in future using a plant's model. MPC showed significant improvement in the WTG control system [18]. However, from practical point of view, the main drawback of MPC is the requirement to solve a quadratic programming problem on line [18].

From the aforementioned research studies, the performance of pitch angle control can be improved using MPC if the predication computational complexity can be overcome. This can be achieved with future knowledge of wind behaviour. Instead of prediction, wind speed information can be passed from one WTG to another. Then, this information can be fed to the MPC to produce the optimal action in advance. In this paper, a new strategy to control the pitch angle proposed. The strategy is based on designing an MPC controller capable of maintaining a stable minimum fluctuating power generation. The concept of the new strategy is based on feeding forward the wind speed information in advance to the WTG. This will allow the controller to take the optimal control action in advance hence minimizing undesired power fluctuation.

This article is organized as follows. In Section 2, the mathematical model of the wind turbine power

Corresponding author: mouayad.sahib@uoitc.edu.iq 
generation is introduced. The proposed control method is presented in section 3 . In section 4 , simulation results and discussion is presented. Finally, section 5 concludes the paper research.

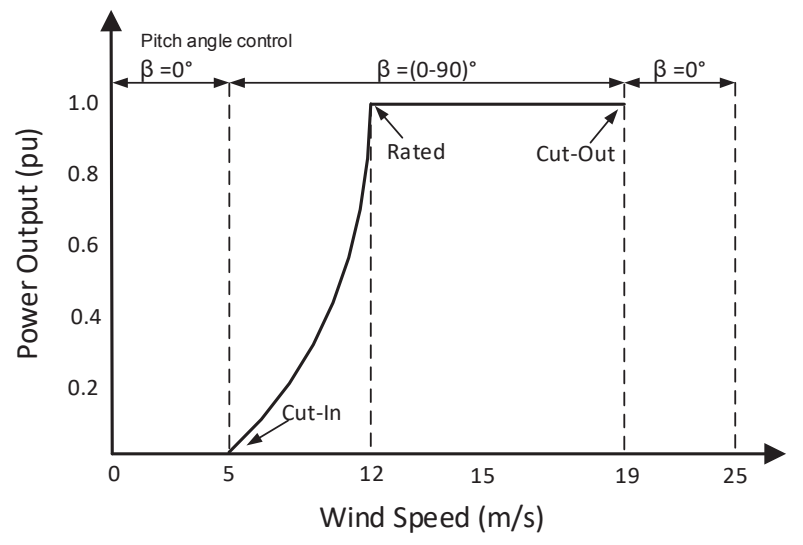

Fig. 1. Operation regions of WTG.

\section{WTG Modelling}

Wind turbine generators extract energy from the wind and convert it into mechanical energy, then into electrical power. The wind power equation is given by [13]:

$$
P=\frac{1}{2} \rho A V^{3}
$$

where, $\rho$ is the air density, $A=\pi R^{2}$ is the circular area swept by the blades of radius $R$, and $V$ is the wind velocity.WTG converts the wind power into electrical power at ideal maximum efficiency of $59 \%$. This power conversion limit is termed as Betz limit [19]. The generated power is expressed by the following nonlinear equation [9]:

$$
P_{g}=\frac{1}{2} \rho A C_{p}(\lambda, \beta) V^{3}
$$

The amount of generated power $\mathrm{P}_{\mathrm{g}}$ extracted from the total wind power is determined by the power coefficient $\mathrm{C}_{\mathrm{p}}$. The power coefficient is a nonlinear function of the blade pitch angle and the blade tip speed ratio $\lambda$ (TSR). The following equation is used to approximate $C_{p}$ in the full load region [5]:

$$
C_{p}=0.22\left(\frac{116}{x}-0.4 \beta-5\right) e^{\frac{-12.5}{x}}
$$

where,

$$
\frac{1}{x}=\frac{1}{\lambda-0.08 \beta}-\frac{0.035}{1+\beta^{3}}
$$

The TSR $\lambda$ is the ratio of the angular rotor speed of the wind turbine to the linear wind speed at the tip of the blades given by:

$$
\lambda=\frac{\omega R}{v}
$$

where $\omega$ is the angular velocity of the turbine rotor $(\mathrm{rad} / \mathrm{s})$ and $\mathrm{v}$ is the wind velocity $(\mathrm{m} / \mathrm{s})$. using equations (3) and (4) the relation of the power factor $C_{p}$ with the $\operatorname{TSR} \lambda$ for different values of the pitch angle $\beta$ is shown in figure 2.

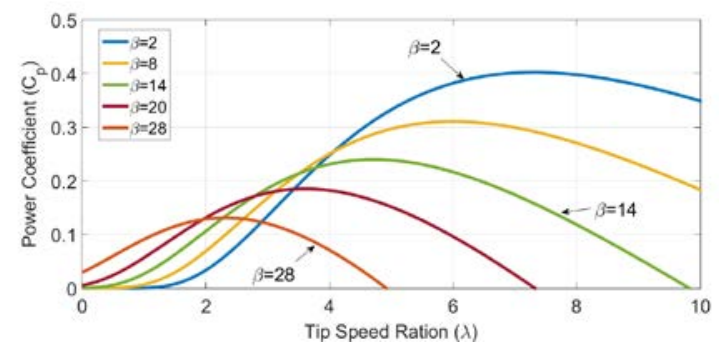

Fig. 2. $C_{p}$ curves vs TSR for different $\beta$.

In each $\mathrm{C}_{\mathrm{p}}$ curve in figure 2 , there is a unique optimal $\operatorname{TSR}\left(\lambda_{\text {opt }}\right)$ value at witch the power coefficient is maximum. In partial-load region (region II), the control objective is to maintain the TSR at its optimal value $\lambda_{\text {opt }}$ with variable wind speed to extract maximum power. However, in full-load region (region III) where the wind speed exceeds the rated value the control objective is to limit power generation. The optimal rotor speed is the rated constant speed $\omega^{*}$. In equation (5), $\lambda$, is inversely proportional to the variation of the wind velocity $\mathrm{v}$. To maintain the power coefficient $C_{p}$ constant, the variation of $\lambda$ is compensated by varying the pitch angle $\beta$ in equations (3) and (4). Therefore, a control method is required to adjust the pitch angle based on the deviation of the output power compared to a set point value equal to the rated power. One common controller used for pitch angle control is the Proportional Integral (PI) controller explained in the following section.

\section{Proposed Control Method}

The conventional pitch angle control system is shown in figure 3.

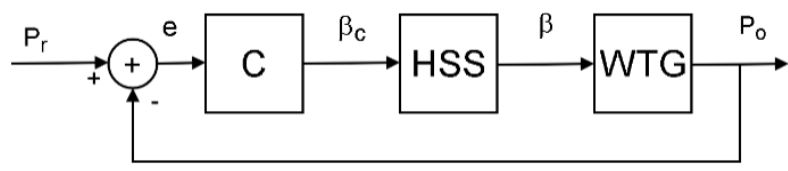

Fig. 3. Pitch angle control system block diagram.

The controller $\mathrm{C}$ is used to command the hydraulic servo system (HSS) with $\beta_{c}$ based on the error signal e between the set point power $\mathrm{P}_{\mathrm{r}}$ and the output power $\mathrm{P}_{\mathrm{o}}$. The HSS is an actuator model used to turn the blades along their longitudinal axis. The HSS model describes the dynamic behaviour between a pitch command $\beta_{\mathrm{c}}$ from the pitch controller and an actuating pitch angle $\beta$ to the WTG. The dynamics of the blades are non-linear with saturation limits on both pitch angle and pitch rate [19]. Due to these limitations the controller performance drops and cannot cope with high wind speed variations affecting the output power. Linear model predictive control (LMPC) can be used together with predictions of 
future wind speed to improve controller performance in above rated wind conditions [17]. However, the controller performance drops due to wind estimation errors.

The proposed control method in this paper is based on providing the MPC with future wind velocity information. Wind information can be transmitted from near WTG tower. In designing the layout of wind farm, a minimum spacing distance (d) between turbines should be taken into consideration. With a wind of velocity $\mathrm{v}$, the time it takes to travel from turbine $i$ to turbine $\mathrm{j}$ is:

$$
t=\frac{d}{v}
$$

The delay time $\mathrm{t}$ represent the maximum prediction horizon used by the MPC controller. When the prediction horizon is well matched to the lag between future and current wind velocities the controller can achieve improved performance.

\section{Simulation Results}

In order to evaluate the performance of the proposed algorithm this section presents and discuss simulation results. The proposed MPS is compared with the conventional PI controller. Table 1 lists the WTG simulation parameters [5].

Table 1. Simulation parameters

\begin{tabular}{|c|c|}
\hline Wind Turbine Parameter & Value \\
\hline Rotor radius $(\mathrm{R})$ & $38 \mathrm{~m}$ \\
\hline Rated rotor speed $\left(\omega_{r}\right)$ & $2.273 \mathrm{rad} / \mathrm{s}$ \\
\hline Air density $(\rho)$ & $1.205 \mathrm{~kg} / \mathrm{m}^{3}$ \\
\hline Cut in wind speed $\left(v_{c i}\right)$ & $5 \mathrm{~m} / \mathrm{s}$ \\
\hline Rated wind speed $\left(v_{r}\right)$ & $12 \mathrm{~m} / \mathrm{s}$ \\
\hline Cut out wind speed $\left(v_{c o}\right)$ & $19 \mathrm{~m} / \mathrm{s}$ \\
\hline Rated power $\left(P_{r}\right)$ & $2 \mathrm{MW}$ \\
\hline Pitch angle limit $(\beta)$ & $0-90^{\circ}$ \\
\hline Pitch rate limit $(\dot{\beta})$ & $\pm 10^{\circ} / \mathrm{s}$ \\
\hline
\end{tabular}

In the simulated scenario, the constraints of the proposed MPC controller are imposed on the control pitch angle. The parameters of the MPC controller are tuned according to the change of the wind speed and the information provided in advance. Moreover, the prediction horizon and the control horizon selected $\mathrm{N}_{\mathrm{p}}=10$, and $\mathrm{N}_{\mathrm{c}}=2$ respectively, with a control interval of $1.0 \mathrm{sec}$. The aim of the MPC controller is to calculate a proper control action in advance. The overall objective of the control design is to stabilize the power output at its rated value which is $2 \mathrm{MW}$. Two types of wind speed profile signals are used in simulation for comparison; sine and square waves. In the sine wave type the wind varies between 12 to $14 \mathrm{~m} / \mathrm{s}$ with frequency equal to $(\pi / 6) \mathrm{rad} / \mathrm{sec}$. However, for the square wave type the wind varies between 12.5 to $13.5 \mathrm{~m} / \mathrm{s}$ with frequency equals to $(\pi / 5) \mathrm{rad} / \mathrm{sec}$. These artificial wind profiles are selected to evaluate the tracking performance of the proposed controller. Figures 4-7 show the performance of the PI and proposed MPC controllers for the two types of wind signal profiles.

It can be observed from figures 4-7 that the proposed MPC controller outperforms the conventional PI controller for both types of wind profiles. The WTG output power has smoother behaviour with the new controller compared to PI.

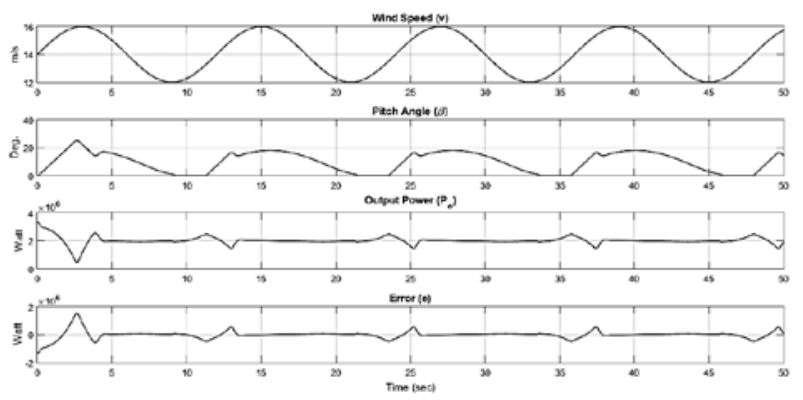

Figure 4, PI controller with sine wave wind profile.

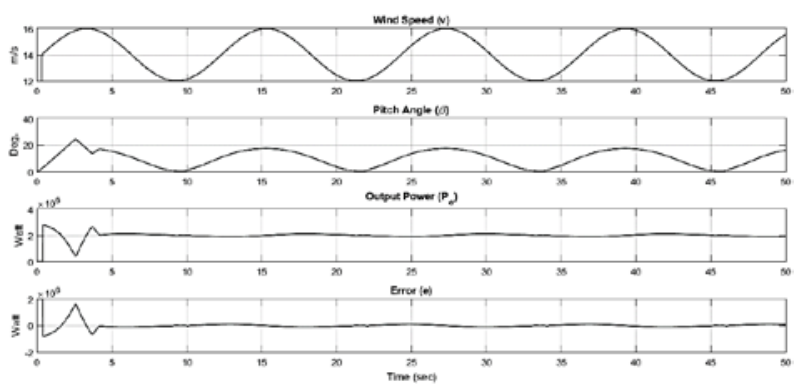

Figure 5, MPC controller with sine wave wind profile.

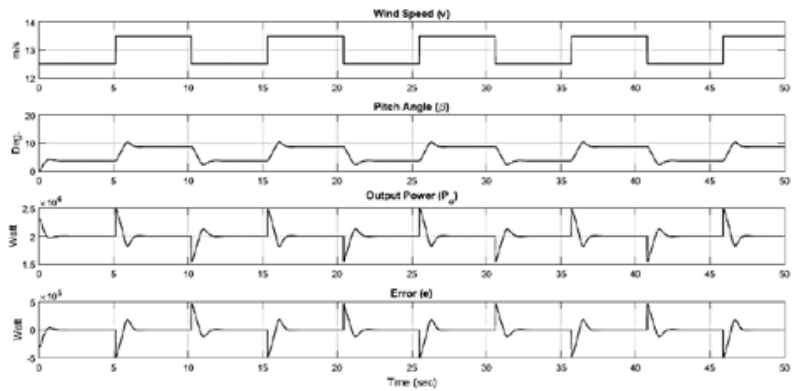

Figure 6, PI controller with square wave wind profile.

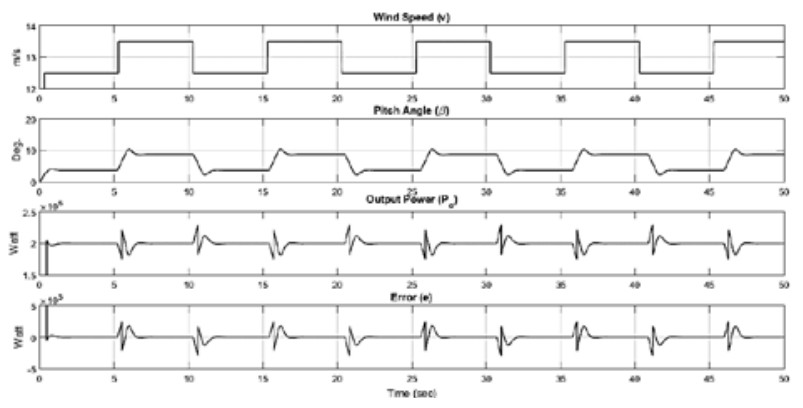

Figure 7, MPC controller with square wave wind profile.

The improved control performance of the proposed MPC is due to the advance action the controller takes to compensate for wind variations. This action is based on the feedforward information of the wind speed provided to the controller. Figure 8, shows a comparison between the PI and the proposed MPC error input signals. As can 
be seen from figure 8, the proposed MPC possess less peaks amplitudes and fluctuations compared to the PI controller for both wind types. Table 2 lists a comparative result between the proposed MPC and PI controllers. The numerical values represent the maximum overshoot and minimum undershoot percentages of the error signals. It is evident that the proposed MPC outperforms the conventional PI in having less output deviation from the rated power.

It is worth noting that, the proposed control strategy can be generalized in a distributed control wind farm system. Each WTG unit acts as an agent to share its current control status and wind speed to advice adjacent control units in calculating the appropriate control action in advance in order to maintain smooth power output.

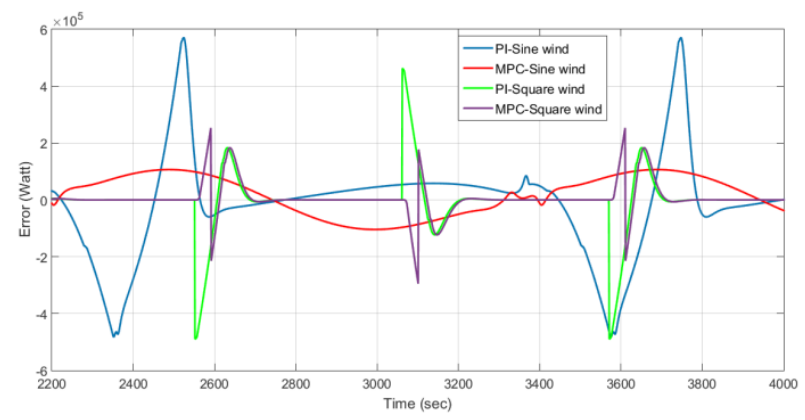

Figure 8, Error Comparison.

Table 2, Performance Comparison.

\begin{tabular}{|c|c|c|c|}
\hline $\begin{array}{c}\text { Controller } \\
\text { Type }\end{array}$ & \multirow{2}{*}{$\begin{array}{c}\text { Wind } \\
\text { Type }\end{array}$} & $\begin{array}{c}\text { Max. } \\
\text { Overshoot } \\
(\%)\end{array}$ & $\begin{array}{c}\text { Min. } \\
\text { Undershoot } \\
(\%)\end{array}$ \\
\hline PI & \multirow{2}{*}{ Sine } & 28.54 & -24.06 \\
\cline { 3 - 4 } & & $\mathbf{0 5 . 3 3}$ & $\mathbf{- 0 5 . 2 1}$ \\
\hline MPC & \multirow{2}{*}{ Square } & 23.11 & -24.48 \\
\cline { 3 - 4 } & $\mathbf{1 2 . 6 6}$ & $\mathbf{- 1 4 . 7 3}$ \\
\hline MPC & &
\end{tabular}

\section{Conclusion}

In this paper a new pitch angle control method is used to smooth wind turbine generator output power. The control strategy is based on providing future wind speed information to a model predictive controller. The wind information is provided (feed forward) from an upstream wind turbine. With this method, the proposed MPC can take the appropriate control action in advance and hence maintain a smooth power generation.

\section{References}

1. R. Sitharthan, C. Sundarabalan, K. Devabalaji, T. Yuvaraj, and A. Mohamed Imran, "Automated power management strategy for wind power generation system using pitch angle controller," Meas. Control, vol. 52, no. 3-4, pp. 169-182, Mar. (2019).

2. D. Ochoa and S. Martinez, "Frequency dependent strategy for mitigating wind power fluctuations of a doubly-fed induction generator wind turbine based on virtual inertia control and blade pitch angle regulation," Renew. Energy, vol. 128, pp. 108-124, Dec. (2018).

3. L. Cavanini, M. L. Corradini, G. Ippoliti, and G. Orlando, "A Control Strategy for Variable-Speed Variable-Pitch Wind Turbines within the regions of partial-and full-load operation without wind speed feedback," in 2018 European Control Conference (ECC), (2018), pp. 410-415.

4. A. Dahbi, N. Nait-Said, and M.-S. Nait-Said, "A novel combined MPPT-pitch angle control for wide range variable speed wind turbine based on neural network," Int. J. Hydrogen Energy, vol. 41, no. 22, pp. 9427-9442, Jun. (2016).

5. H. Matayoshi, A. M. Howlader, M. Datta, and T. Senjyu, "Control strategy of PMSG based wind energy conversion system under strong wind conditions," Energy Sustain. Dev., vol. 45, pp. 211218, Aug. (2018).

6. M. Ben Smida and A. Sakly, "Smoothing wind power fluctuations by particle swarm optimizationbased pitch angle controller," Trans. Inst. Meas. Control, vol. 41, no. 3, pp. 647-656, Feb. (2019).

7. Y.-J. Joo and J.-H. Back, "Power Regulation of Variable Speed Wind Turbines using Pitch Control based on Disturbance Observer," J. Electr. Eng. Technol., vol. 7, no. 2, pp. 273-280, Mar. (2012).

8. Y. Ren, L. Li, J. Brindley, and L. Jiang, "Nonlinear PI control for variable pitch wind turbine," Control Eng. Pract., vol. 50, pp. 84-94, May (2016).

9. M. Oussama, A. Choucha, and L. Chaib, "Fractional Order PI Controller Design for Control of Wind Energy Conversion System Using Bat Algorithm," in Lecture Notes in Networks and Systems, vol. 62, Springer, Cham, (2019), pp. 270-278.

10. D. Song et al., "A novel wind speed estimatorintegrated pitch control method for wind turbines with global-power regulation," Energy, vol. 138, pp. 816-830, Nov. 2017.

11. J. Lan, R. J. Patton, and X. Zhu, "Fault-tolerant wind turbine pitch control using adaptive sliding mode estimation," Renew. Energy, vol. 116, pp. 219-231, Feb. (2018).

12. T. L. Van, N. K. Dang, X. N. Doan, T. H. Truong, and H. N. Minh, "Adaptive Fuzzy Logic Control to Enhance Pitch Angle Controller for Variable-Speed Wind Turbines," in 2018 10th International Conference on Knowledge and Systems Engineering (KSE), (2018), pp. 225-229.

13. Z. Civelek, M. Lüy, E. Çam, and H. Mamur, "A new fuzzy logic proportional controller approach applied to individual pitch angle for wind turbine load mitigation," Renew. Energy, vol. 111, pp. 708-717, Oct. (2017).

14. K. A. Naik and C. P. Gupta, "Fuzzy logic based pitch angle controller/or SCIG based wind energy system," in 2017 Recent Developments in Control, Automation \& Power Engineering (RDCAPE), (2017), pp. 60-65. 
15. M. L. Corradini, G. Ippoliti, and G. Orlando, "An observer-based blade-pitch controller of wind turbines in high wind speeds," Control Eng. Pract., vol. 58, pp. 186-192, Jan.( 2017).

16. A. G. Alexandrov, V. N. Chestnov, and V. A. Alexandrov, "Identification Based Control For Wind Turbine," IFAC-PapersOnLine, vol. 50, no. 1, pp. 2272-2277, Jul. (2017).

17. M. D. Spencer, K. A. Stol, C. P. Unsworth, J. E. Cater, and S. E. Norris, "Model predictive control of a wind turbine using short-term wind field predictions," Wind Energy, vol. 16, no. 3, pp. 417434, Apr. (2013).

18. J. Pahasa and I. Ngamroo, "Model predictive control-based wind turbine blade pitch angle control for alleviation of frequency fluctuation in a smart grid," in 2014 International Electrical Engineering Congress (iEECON), (2014), pp. 1-4.

19. A. Hwas and R. Katebi, "Wind Turbine Control Using PI Pitch Angle Controller," IFAC Proc. Vol., vol. 45, no. 3, pp. 241-246, Jan. (2012). 